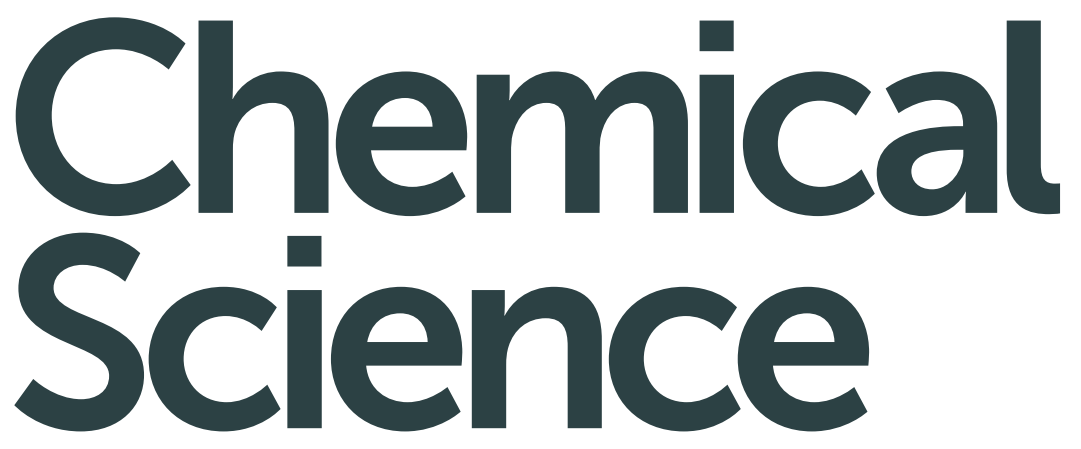

rsc.li/chemical-science

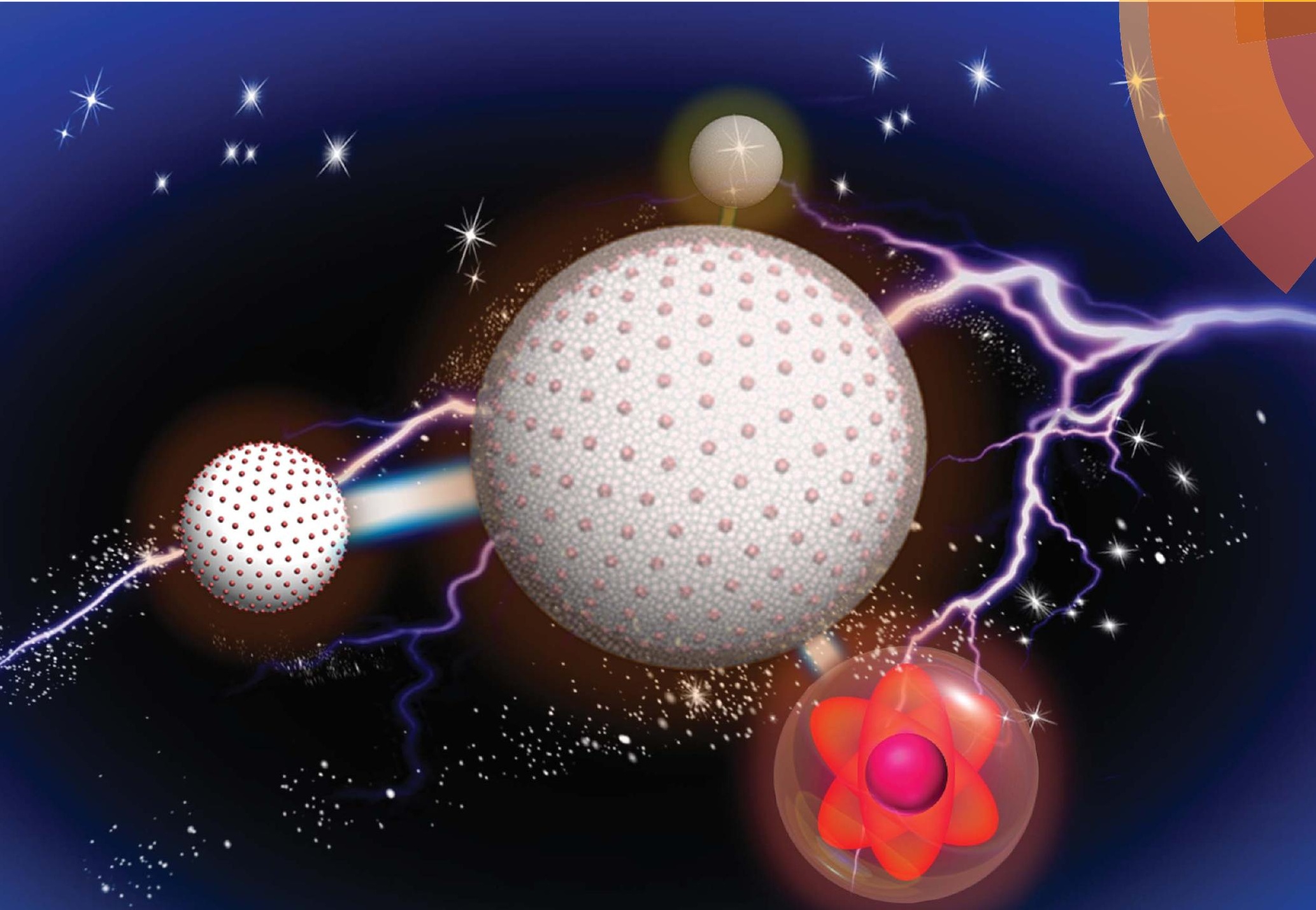

ISSN 2041-6539

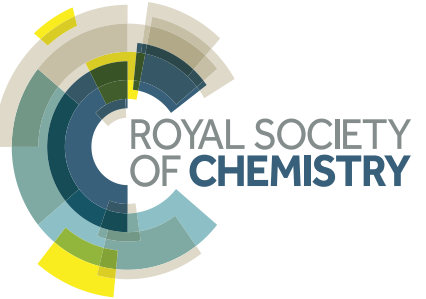


Check for updates

Cite this: Chem. Sci., 2018, 9, 8914

๑ All publication charges for this article have been paid for by the Royal Society of Chemistry

Received 9th October 2018

Accepted 15th November 2018

DOI: $10.1039 /$ c8sc04479a

rsc.li/chemical-science

\section{Tunable plasmonic core-shell heterostructure design for broadband light driven catalysis $\uparrow$}

\author{
Chuang Han, ${ }^{\text {ab }}$ Shao-Hai Li, ${ }^{\text {ab }}$ Zi-Rong Tang (D) ${ }^{b}$ and Yi-Jun Xu (D)*ab
}

Considerable effort has been devoted to manipulating the optical absorption of metal nanostructures for diverse applications. However, it still remains a challenge to develop a general and flexible method to promote broadband absorption of metal nanostructures without changing their size and shape. Here, we report a new strategy of hybridizing two conceptually different optical models to realize broadband absorption enhancement of metal nanoparticles (NPs), which is enabled by constructing a core-shell heterostructure, consisting of a spherical dielectric core covered by a metal NPs interlayer and tunable semiconductor shell. This approach integrates the interfacial photon management, photoexcitation of metal NPs and injection of hot charge carriers into the semiconductor shell, and results in distinctly enhanced hot charge carrier generation and transfer, thereby boosting the broad-spectrum light driven catalysis. The structure-plasmon-catalysis interplay of the heterostructure is comprehensively studied and optimized. This proof-of-concept proves to be generally feasible by varying the type of both metal NPs and support medium, opening a new avenue to control the optoelectronic properties of materials.

\section{Introduction}

Surface plasmon resonance (SPR), resulting from the collective oscillations of delocalized electrons in a metal particle, ${ }^{1-4}$ offers great opportunity to design tailored light absorption materials for solar-to-chemical (or electric) energy conversion without the bandgap limitations of traditional semiconductor materials..$^{5-10}$ However, the inherent drawbacks such as the limited spectral range of low-loss plasmon resonance, weak light absorption intensity and rapid hot charge carrier relaxation fundamentally restrict the solar energy conversion efficiency of plasmonic metals. ${ }^{7-9,11}$ Various strategies have been developed to tune the optical absorption and prolong the lifetime of hot charge carriers of plasmonic metals, thereby boosting the efficiency of photoredox reactions. ${ }^{7-9,12-17}$ Notably, these strategies have predominantly relied on altering the nature (e.g., size, shape or type) of metal nanostructures and coupling with other metals to maximize light-matter interaction and energy transfer. It is still challenging to develop a general and cost-efficient method to simultaneously promote the broad-spectrum light absorption and hot charge carrier separation and transfer of metal nanostructures, but without synthetically changing their size and shape.

Light scattering by dielectric spherical particles gives rise to electronic field enhancement and photon confinement at the

\footnotetext{
${ }^{a}$ State Key Laboratory of Photocatalysis on Energy and Environment, College of Chemistry, Fuzhou University, Fuzhou, 350116, China. E-mail: yjxu@fzu.edu.cn ${ }^{b}$ College of Chemistry, New Campus, Fuzhou University, Fuzhou, 350116, China

$\dagger$ Electronic supplementary information (ESI) available: Experimental details, 15 figures and 4 tables. See DOI: 10.1039/c8sc04479a
}

interface that can be used to enhance the light harvesting efficiency. ${ }^{18-20}$ Theoretical studies have predicted that when nearfield scattering radiation overlaps with SPR, hybrid resonance modes generally occur and specific optical absorption enhancement will emerge. ${ }^{21,22}$ Yet, it still remains unknown whether the combination of these two conceptually different strategies, i.e., expanding the light response region by the SPR effect and enhancing light absorption intensity with a near-field scattering optical model, could be expected to combinatively manipulate interfacial photon interaction, enhance the light harvesting capability of plasmonic metal NPs in a broadband spectral range, and result in the boosted generation and separation of hot charge carriers for improved photoredox catalysis performance.

Since both near-field scattering and SPR are greatly dependent on the geometrical arrangement of the building units, ${ }^{5,23}$ a systematic study on these two optical cooperative effects will lead us to ultimately unveil the whole scenario of how the heterointerface and compositions of metal-dielectric sphere hybrid structures affect the light absorption properties of plasmonic metal NPs and the corresponding photocatalytic performance triggered by light-excited hot charge carriers from plasmonic metal NPs, which will further guide the design and optimization of the plasmonic photocatalyst.

Herein, we report a general and cost-efficient paradigm of core-shell heterostructure design for broadband light absorption management of plasmonic metal NPs without changing their size and shape. This approach mainly involves construction of a three dimensional (3D) core-shell nanostructure consisting of a spherical $\mathrm{SiO}_{2}$ core covered by a plasmonic Au NPs 
interlayer and tunable $\mathrm{TiO}_{2}$ semiconductor shell. In such a heterostructure, the multiple light-matter interactions at the core-shell interfaces enable tuning and enhancing the optical absorption of plasmonic Au NPs across the ultraviolet-visiblenear infrared (UV-vis-NIR) region. The plasmonic Au NPs can harvest broadband light to generate and inject hot charge carriers into $\mathrm{TiO}_{2}$ for driving surface redox reactions. The light absorption and photoactivity enhancement is highly dependent on the diameter of the spherical dielectric core, the type of metal NPs and the thickness of the semiconductor shell. The generality of this strategy has been proven by varying both the metal NPs (plasmonic Ag or nonplasmonic Pt NPs) and support medium (e.g., $\mathrm{TiO}_{2}, \mathrm{ZnO}$, and organic polymer polystyrene) of the core-shell composite. Our work suggests promising scope to adopt this new methodology of coupling the SPR model of a plasmonic metal with a near-field scattering optical model to control the structure-plasmon-catalysis interplay of plasmonic metal nanostructures, thereby realizing efficient broadband light driven catalysis.

\section{Experimental section}

\section{Preparation}

$\mathrm{Au}-\mathrm{SiO}_{2}$ composites with different weight contents of Au were prepared by a facile electrostatic self-assembly method using negatively charged citrate-stabilized Au NPs and positively charged 3-aminopropyl-triethoxysilane (APTES)-functionalized $\mathrm{SiO}_{2}$ spheres in the aqueous phase. ${ }^{18,24}$ The $\mathrm{Au}-\mathrm{SiO}_{2} @ \mathrm{TiO}_{2}$ composites were synthesized by coating a $\mathrm{TiO}_{2}$ shell on the surface of $\mathrm{Au}-\mathrm{SiO}_{2}$ using a cooperative assembly-directed procedure. ${ }^{25}$ For more experimental details see the Methods in the ESI. $\dagger$

\section{Characterization}

Zeta potential $(\xi)$ measurements of the samples were performed by dynamic light scattering analysis (Zeta sizer 3000HSA) at room temperature. The optical properties of the samples were measured by ultraviolet-visible-near infrared (UV-vis-NIR) diffuse reflectance spectroscopy (DRS) on a UV-vis Spectrophotometer (Thermo Scientific Evolution 200 Series) with $\mathrm{BaSO}_{4}$ as the internal reflectance standard. The content of Au was measured by inductively coupled plasma mass spectrometry (ICP-MS, XSERISE 2). The morphology and elemental distribution of the samples were analyzed by field-emission scanning electron microscopy (FESEM) on a FEI Nova NANOSEM 230 spectrophotometer and transmission electron microscopy (TEM), high-resolution TEM (HRTEM), energy dispersive X-ray spectroscopy (EDX) and elemental mapping analysis using a JEOL model JEM 2010 EX instrument at an accelerating voltage of $200 \mathrm{kV}$. Micromeritics ASAP2010 equipment was used to determine the nitrogen adsorption-desorption isotherms and the Brunauer-Emmett-Teller (BET) surface areas. The sample was degassed at $140{ }^{\circ} \mathrm{C}$ for $5 \mathrm{~h}$ and then analyzed at $-196{ }^{\circ} \mathrm{C}$. The transient absorption (TA) data were measured by using femtosecond transient absorption spectroscopy (TimeTech Spectra, femtoTA-100). Part of the $800 \mathrm{~nm}$ output pulse from the amplifier was used to pump a TOPAS Optical Parametric Amplifier (OPA) which generates a $400 \mathrm{~nm}$ pump beam. The pump pulses were chopped with a synchronized chopper at $500 \mathrm{~Hz}$ and the absorbance change was calculated with two adjacent probe pulses (pump-blocked and pump-unblocked), and the pump pulse power was approximately $70 \mu \mathrm{J} \mathrm{cm}^{-2}$. The samples were dispersed in ethylene glycol for all pump-probe characterization experiments performed under ambient conditions. The electrochemical analysis was carried out in a conventional three-electrode cell using a Pt plate and an Ag/ $\mathrm{AgCl}$ electrode as the counter electrode and reference electrode, respectively. The working electrode was prepared on fluorinedoped tin oxide (FTO) glass that was cleaned by sonication in ethanol for $30 \mathrm{~min}$ and dried at $80^{\circ} \mathrm{C}$. The boundary of the FTO glass was protected using Scotch tape. A $10 \mathrm{mg}$ sample was dispersed in $1 \mathrm{~mL}$ of DMF by sonication to get a slurry. The slurry was spread onto the pretreated FTO glass. After air drying, the working electrode was further dried at $120{ }^{\circ} \mathrm{C}$ for $2 \mathrm{~h}$ to improve adhesion. Then, the Scotch tape was unstuck, and the uncoated part of the electrode was isolated with epoxy resin. The exposed area of the working electrode was $0.25 \mathrm{~cm}^{2}$. The photocurrent density was measured on a BAS Epsilon workstation without bias. The electrolyte was $0.2 \mathrm{M} \mathrm{Na}_{2} \mathrm{SO}_{4}$ aqueous solution. Incident photon-to-current conversion efficiency (IPCE) was measured by using a PEC-S20 (Peccell Technology Co. Ltd.) without bias potential. The IPCE value was calculated according to the following equation: ${ }^{\mathbf{1 1 , 1 8}}$

$$
\mathrm{IPCE}=\frac{1240 \times J_{\mathrm{ph}}}{\lambda \times I_{\text {light }}} \times 100 \%
$$

where $J_{\mathrm{ph}}$ is the photocurrent density, $\lambda$ is the incident light wavelength, and $I_{\text {light }}$ is the incident light power density for each wavelength.

\section{Photoactivity testing}

In a typical procedure for photocatalytic reduction of nitro compounds, a $300 \mathrm{~W}$ Xe arc lamp (PLS-SXE 300, Beijing Perfect light Co., Ltd.) with a filter (Shanghai Mega-9 Optoelectronic Co., Ltd.) to cut off the light of wavelengths $\lambda<410 \mathrm{~nm}$ was used as the irradiation source. The light intensity was fixed at 800 $\mathrm{mW} \mathrm{cm}{ }^{-2} .20 \mathrm{mg} \mathrm{Au}-\mathrm{SiO}_{2}$ or $25 \mathrm{mg}$ core-shell Au-SiO @TiO $_{2}$ and $80 \mathrm{mg}$ of ammonium formate (as a quencher for photogenerated holes) were added to $40 \mathrm{~mL}$ of the nitroaromatic solution $\left(5 \mathrm{mg} \mathrm{L}^{-1}\right)$ in a quartz vial. Before light illumination, the above suspension was stirred in the dark for $1 \mathrm{~h}$ to ensure the establishment of adsorption-desorption equilibrium between the sample and reactant. During the process of the reaction, $2 \mathrm{~mL}$ of sample solution was collected at a certain time interval and centrifuged to remove the catalyst completely at $12000 \mathrm{rpm}$. Afterward, the solution was analyzed on a Varian UV-vis Spectrophotometer. The whole experimental process was conducted at room temperature under $\mathrm{N}_{2}$ bubbling at a flow rate of $80 \mathrm{~mL} \mathrm{~min}{ }^{-1}$. The photodeposition of $\mathrm{Ag}$ was conducted under identical conditions except that nitroaromatic solution was replaced by $40 \mathrm{~mL}$ of $0.01 \mathrm{M} \mathrm{AgNO}_{3}$ solution. In photocatalytic oxidation of alcohols, a mixture of an alcohol (0.1 
mmol) and photocatalyst was dispersed in oxygen-saturated benzotrifluoride (BTF; $1.5 \mathrm{~mL}$ ). The mixture was transferred into a $10 \mathrm{ml}$ Pyrex glass bottle filled with molecular oxygen at a pressure of 0.1 MPa and stirred for half an hour to blend the catalyst evenly into the solution. The suspensions were irradiated with visible-near infrared (vis-NIR, $410 \mathrm{~nm}<\lambda<1100 \mathrm{~nm}$ ) light. After the reaction, the product and remaining substrate were analyzed with an Agilent Gas Chromatograph (GC-7820). To obtain the action spectrum, the reaction system was continuously illuminated under nearly monochromatic light with a light intensity of $40 \mathrm{~mW} \mathrm{~cm}^{-2}$ for $10 \mathrm{~h}$. The recycling testing and control experiments were conducted under identical conditions to those of the photocatalytic reaction as mentioned above. The conversion (\%) of the aromatic nitro compounds and benzylic alcohols during the photocatalytic reaction is reported as $\left(C_{0}-C\right) / C_{0} \times 100 \%$, where $C_{0}$ is the initial concentration of the reactant after the establishment of adsorption desorption equilibrium, and $C$ is the concentration of the reactant at a certain time interval after the photocatalytic reaction.

\section{Results and discussion}

\section{Synthesis and morphology analysis}

Efficient harvesting of solar energy to generate hot charge carriers requires that the plasmonic metal nanostructures have strong and broadband light absorption. ${ }^{26}$ Here, we achieve the broadband optical absorption of plasmonic metal NPs by adjusting their dielectric environment, while preserving the size of metal NPs. Taking the plasmonic Au NPs as an example, the generic procedure mainly involves uniform self-assembly of $\mathrm{Au}$ NPs onto the surface of 3-aminopropyl-triethoxysilane (APTES)modified $\mathrm{SiO}_{2}$ spheres to synthesize $\mathrm{Au}-\mathrm{SiO}_{2}$ by electrostatic attraction (Fig. S1a $\dagger$ ), and subsequently coating a tunable thinlayer of $\mathrm{TiO}_{2}$ over $\mathrm{Au}-\mathrm{SiO}_{2}$ using a cooperative assemblydirected process, ${ }^{25}$ as illustrated in Fig. 1a. The morphologies of $\mathrm{SiO}_{2}$ and $\mathrm{Au}-\mathrm{SiO}_{2}$ are shown in Fig. $1 \mathrm{~b}$ and c, respectively. As compared to the smooth surface of bare $\mathrm{SiO}_{2}$ spheres (Fig. 1b), the anchored $\mathrm{Au}$ NPs with a mean size of $5.5 \mathrm{~nm}$ (Fig. S1b and $\mathrm{S} 1 \mathrm{c} \dagger$ ) can be clearly observed on the surface of $\mathrm{Au}-\mathrm{SiO}_{2}$ (Fig. 1c). The intimate interfacial contact between $\mathrm{SiO}_{2}$ and $\mathrm{Au}$ NPS (Fig. S1d $\dagger$ ) assured by surface modification of $\mathrm{SiO}_{2}$ through APTES allows an efficient light-matter interaction between them. ${ }^{18}$

For the $\mathrm{Au}-\mathrm{SiO}_{2} @ \mathrm{TiO}_{2}$ composite, the scanning electron microscopy (SEM) and transmission electron microscopy (TEM) images (Fig. 1d and e) indicate that $\mathrm{Au}-\mathrm{SiO}_{2}$ is well covered by the $\mathrm{TiO}_{2}$ shell with an average thickness of $11 \mathrm{~nm}$. Notably, the developed cooperative assembly-directed method enables us to tune the shell thickness by controlling the additive volume of the titanium precursor (for more details, see the Methods in the ESI and Fig. S2 $\dagger){ }^{25}$ The Au NPs embedded into the $\mathrm{TiO}_{2}$ shell with a similar size and shape to those in $\mathrm{Au}-\mathrm{SiO}_{2}$ are clearly distinguished. The $\mathrm{Au}-\mathrm{SiO}_{2} @ \mathrm{TiO}_{2}$ composite also exhibits a spherical shape, indicating a uniform coating layer of $\mathrm{TiO}_{2}$ over the entire surface of $\mathrm{Au}-\mathrm{SiO}_{2}$. Energy dispersive X-ray (EDX) elemental mapping in Fig. 1f shows the spatial distributions of

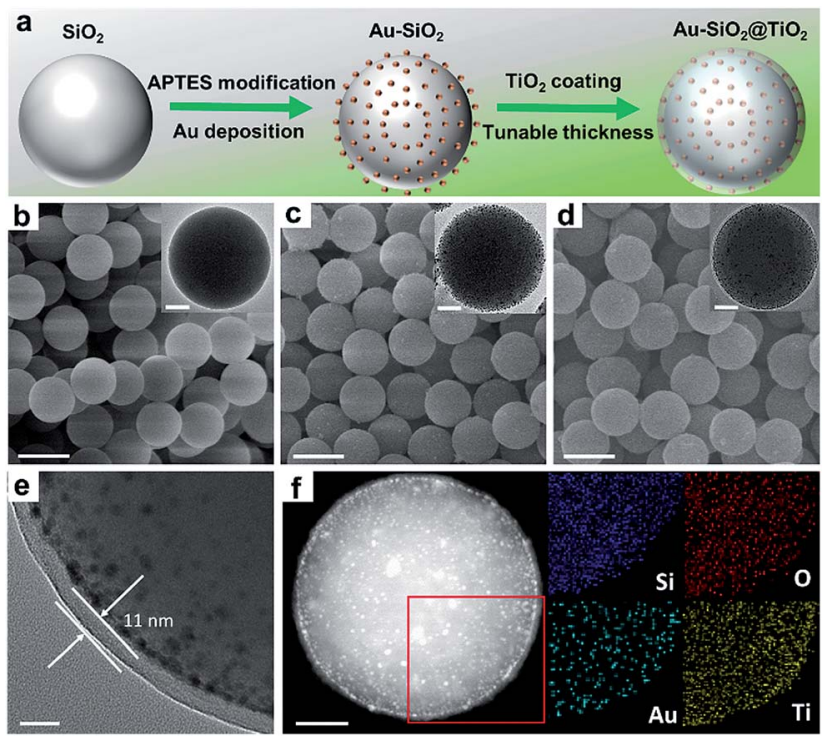

Fig. 1 (a) Schematic illustration of the fabrication process of the Au$\mathrm{SiO}_{2} \mathrm{aTiO}_{2}$ composite. Scanning electron microscopy (SEM) images of (b) bare $\mathrm{SiO}_{2}$, (c) $5 \% \mathrm{Au}-\mathrm{SiO}_{2}$ and (d) $5 \% \mathrm{Au}-\mathrm{SiO}_{2} \mathrm{aTiO}_{2}$. Scale bar, 500 $\mathrm{nm}$. The insets in $(\mathrm{b}-\mathrm{d})$ show the transmission electron microscopy (TEM) images of the corresponding samples. Scale bar, $100 \mathrm{~nm}$. (e) TEM image of $5 \% \mathrm{Au}-\mathrm{SiO}_{2} \mathrm{CTiO}_{2}$ with a shell thickness of $11 \mathrm{~nm}$. Scale bar, $20 \mathrm{~nm}$. (f) High-angle annular dark-field scanning transmission electron microscopy (HAADF-STEM) image (left) and elemental mapping results for the boxed area in the main image of $5 \% \mathrm{Au}-$ $\mathrm{SiO}_{2} \mathrm{OTiO}_{2}$ with a shell thickness of $11 \mathrm{~nm}$. Scale bar, $100 \mathrm{~nm}$.

$\mathrm{Si}, \mathrm{O}, \mathrm{Au}$ and $\mathrm{Ti}$ elements, in which the spatial distribution ranges of $\mathrm{Ti}$ and $\mathrm{O}$ are larger than that of $\mathrm{Au}$ and $\mathrm{Si}$, indicating that the $\mathrm{TiO}_{2}$ thin-layer is coated on the outermost surface of $\mathrm{Au}-\mathrm{SiO}_{2}$ to form such a 3D core-shell structured $\mathrm{Au}-\mathrm{SiO}_{2} @ \mathrm{TiO}_{2}$ composite.

\section{Interface-induced broadband optical absorption}

To verify the enhancement of light harvesting in this core-shell structure model, the optical properties of the samples were characterized. As shown in Fig. 2a, the bare aqueous Au NPs with a mean size of $5.5 \mathrm{~nm}$ exhibit a single SPR absorption centered at $515 \mathrm{~nm}$. When these Au NPs are assembled onto the surface of $\mathrm{SiO}_{2}$ spheres (with a diameter of about $450 \mathrm{~nm}$ ), three distinct absorption modes located at $\sim 360,525$ and $840 \mathrm{~nm}$ appear in the UV-vis-NIR diffuse reflectance spectra (DRS) of $\mathrm{Au}-\mathrm{SiO}_{2}$, resulting in a large spectral overlap with the solar irradiance in the visible-near infrared (vis-NIR) region (Fig. 2b). The peak at $525 \mathrm{~nm}$ is attributed to the characteristic SPR absorption of Au NPs. Compared to the aqueous dispersion of $\mathrm{Au}$ NPs, the SPR absorption peak in $\mathrm{Au}-\mathrm{SiO}_{2}$ is red-shifted by 10 $n m$ due to the higher refractive index of $\mathrm{SiO}_{2}(n=1.55)$ than that of water $(n=1.33) .{ }^{27,28}$ The other two absorption peaks cannot be detected for either bare $\mathrm{SiO}_{2}$ spheres or Au NPs aqueous dispersion. In addition, with the increase of the $\mathrm{Au}$ weight content in the $\mathrm{Au}-\mathrm{SiO}_{2}$ composite, the intensities of these absorption peaks gradually enhance while their peak positions almost remain unchanged, thereby indicating that these 

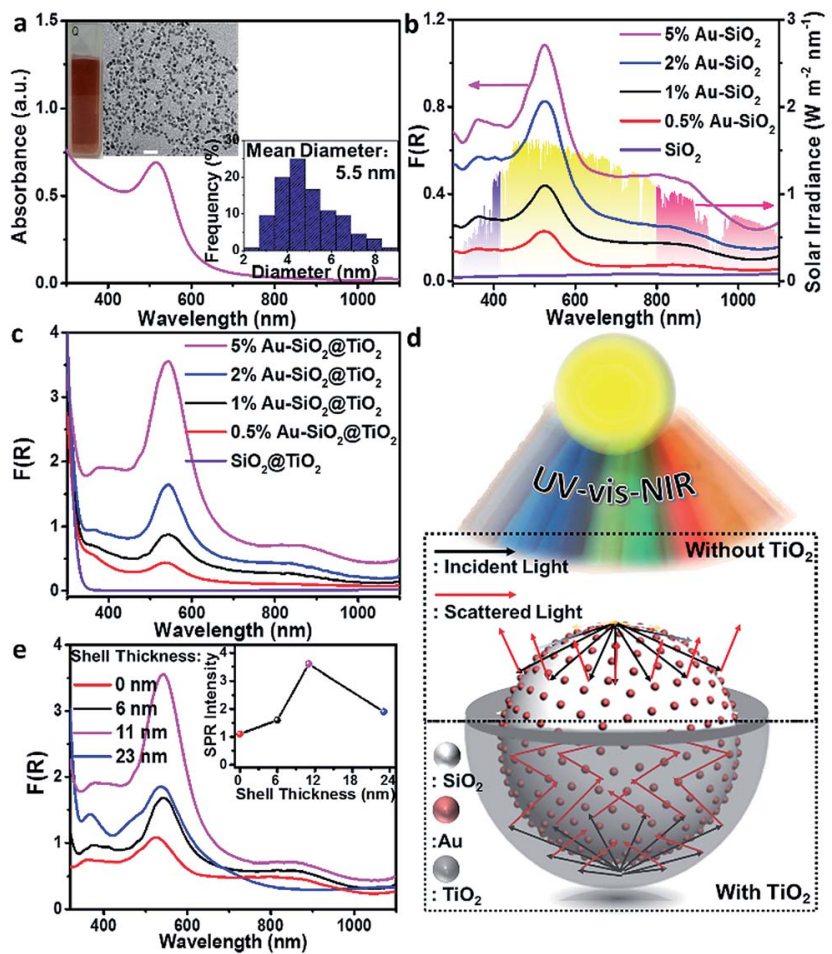

Fig. 2 (a) Ultraviolet-visible-near infrared (UV-vis-NIR) absorption spectrum of Au NPs. The insets in (a) show the photograph, transmission electron microscopy (TEM) image and size distribution histogram of Au NPs colloids. Scale bar, $20 \mathrm{~nm}$. UV-vis-NIR diffuse reflectance spectra (DRS) of (b) $\mathrm{Au}-\mathrm{SiO}_{2}$ and (c) $\mathrm{Au}-\mathrm{SiO}_{2} \mathrm{CTiO}_{2}$ with a shell thickness of $11 \mathrm{~nm}$ with different weight contents of $\mathrm{Au}$. (d) Schematic illustration of the interfacial photon management in $\mathrm{Au}-$ $\mathrm{SiO}_{2}$ and $\mathrm{Au}-\mathrm{SiO}_{2} \mathrm{aTiO}_{2}$. (e) UV-vis-NIR DRS of $5 \% \mathrm{Au}-\mathrm{SiO}_{2} \mathrm{CTiO}_{2}$ with different shell thicknesses. The inset in (e) shows the surface plasmon resonance (SPR) absorption intensity as a function of the average shell thickness of $\mathrm{Au}-\mathrm{SiO}_{2} \mathrm{aTiO}_{2}$. The diameter of $\mathrm{SiO}_{2}$ is $450 \mathrm{~nm}$.

characteristic peaks of $\mathrm{Au}-\mathrm{SiO}_{2}$ are ascribed to the near-field scattering light-matter interaction between $\mathrm{SiO}_{2}$ spheres and $\mathrm{Au}$ NPs, ${ }^{\mathbf{1 8 , 2 9}}$ rather than the interparticle coupling effect or aggregation of Au NPs as reported by previous studies. ${ }^{28,30-32}$

DRS spectra of the $\mathrm{Au}-\mathrm{SiO}_{2} @ \mathrm{TiO}_{2}$ composites with different $\mathrm{Au}$ weight contents are shown in Fig. 2c, where three welldefined absorption peaks at $\sim 365,540$ and $880 \mathrm{~nm}$ can be distinguished. As compared to $\mathrm{Au}-\mathrm{SiO}_{2}$ containing the same amount of $\mathrm{Au}$ NPs, these peaks are slightly red-shifted and greatly intensified due to the coating of the $\mathrm{TiO}_{2}$ shell. ${ }^{18,21,33}$ The intensity of SPR absorption located at $\sim 540 \mathrm{~nm}$ increases almost linearly with increasing the weight content of $\mathrm{Au}$ in the $\mathrm{Au}-\mathrm{SiO}_{2} @ \mathrm{TiO}_{2}$ composite, as shown in Fig. S3. $\dagger$ These results indicate that the $\mathrm{TiO}_{2}$ shell with a high refractive index ( $n=$ 2.49) could serve as an effective reflecting layer to modify internal light reflection and greatly increase the chance of $\mathrm{Au}$ NPs to absorb photons, as demonstrated in Fig. 2 d. ${ }^{20,33-35}$ We also noted that, apart from the peak at $\sim 540 \mathrm{~nm}$ ascribed to the SPR absorption of Au NPs, the other two peaks have not been observed in previously reported Au NPs-semiconductor composites. ${ }^{24,33,36-40}$ In addition, no distinct absorption peak can be observed for $\mathrm{SiO}_{2} @ \mathrm{TiO}_{2}$, except the intrinsic exciton absorption edge of $\mathrm{TiO}_{2}$. These results reveal that the proper control of the configurations such as the internal structure organization and shell thickness is crucial to achieve the broadspectrum light absorption of the $\mathrm{Au}-\mathrm{SiO}_{2} @ \mathrm{TiO}_{2}$ composite. The tunable core-shell ensemble provides a flexible platform for investigating the influence of these factors on the photoabsorption of plasmonic Au NPs.

We then explored the effects of $\mathrm{TiO}_{2}$ shell thickness on the photoabsorption of supported Au NPs. DRS spectra of $\mathrm{Au}^{-}$ $\mathrm{SiO}_{2} @ \mathrm{TiO}_{2}$ with different thicknesses of the $\mathrm{TiO}_{2}$ shell (Fig. 2e) suggest that the peak positions of resonance absorption are not sensitive to the change in $\mathrm{TiO}_{2}$ shell thickness, while the peak intensity exhibits hump-like dependence on the coating thickness of the $\mathrm{TiO}_{2}$ shell, as shown in the inset of Fig. 2e. With increasing the thickness of the $\mathrm{TiO}_{2}$ shell, the absorption intensity initially enhances and reaches a maximum when the thickness of $\mathrm{TiO}_{2}$ is $11 \mathrm{~nm}$. Excessive coating of the $\mathrm{TiO}_{2}$ shell will enhance the external photon reflection by $\mathrm{TiO}_{2}$ rather than photon harvesting of $\mathrm{Au}$ NPs at the core-shell interface, due to the relatively large size of the core-shell composite, ${ }^{\mathbf{4 0 - 4 2}}$ which finally leads to the decrease of absorption intensity and even vanishing of the nearfield scattering-mediated absorption model.

Next, we investigated the effects of the internal core on tuning the optical absorption of Au NPs by varying the diameter of $\mathrm{SiO}_{2}$ spheres (Fig. S4 $\dagger$ ) from $150 \mathrm{~nm}$ to $600 \mathrm{~nm}$. It can be seen from the DRS results in Fig. $\mathrm{S} 5 \dagger$ that small-sized $\mathrm{SiO}_{2}$ spheres (with a diameter $<350 \mathrm{~nm}$ ) have only affected the photoabsorption of Au NPs in the ultraviolet region. As the size of the $\mathrm{SiO}_{2}$ sphere becomes larger, more absorption modes are observed within the UV-vis-NIR region. When the diameter of the $\mathrm{SiO}_{2}$ sphere is larger than $400 \mathrm{~nm}$, the $\mathrm{Au}-\mathrm{SiO}_{2}$ sample exhibits a new absorption band in the near infrared (NIR) region. In addition, the absorption maxima of $\mathrm{Au}-\mathrm{SiO}_{2}$ show an obvious red-shift along with the increment of the $\mathrm{SiO}_{2}$ diameter. Generally, for Au NPs, only those larger than $50 \mathrm{~nm}$ or largesized aggregates can disclose a noticeable NIR absorption band..$^{30,43,44}$ Our results indicate that by merely modulating the diameter of $\mathrm{SiO}_{2}$ supports, the absorption spectrum of small $\mathrm{Au}$ NPs $(<10 \mathrm{~nm})$ supported on spherical $\mathrm{SiO}_{2}$ can be delicately tuned to the NIR region. This result inspires us to find out whether it is possible to tune the optical properties of Au NPs by using other types of spherical supports. In this context, we further studied the interfacial photon interaction between $\mathrm{Au}$ NPs and a series of other dielectric spheres including inorganic semiconductors (e.g., $\mathrm{TiO}_{2}$ and $\mathrm{ZnO}$ ) and organic polymer polystyrene (PS). UV-vis-NIR DRS spectra (Fig. S6†) of these composites suggest that the self-assembly of an Au NPs antenna layer onto a spherical dielectric support is a general method to maneuver the photoabsorption of Au NPs without changing their size.

To uncover the synergistic interaction between metal NPs and the spherical core and understand the fundamental role of metal NPs played in this model system, other metal NPs such as $\mathrm{Ag}$ and Pt NPs (Fig. S7†) were also loaded onto the spherical supports $\left(\mathrm{SiO}_{2}, \mathrm{TiO}_{2}, \mathrm{ZnO}\right.$ and $\left.\mathrm{PS}\right)$ by using the same selfassembly approach. The UV-vis-NIR DRS results in Fig. S8 $\dagger$ 
reveal an analogous absorption enhancement with additional distinct absorption peaks on $\mathrm{Ag}$ or $\mathrm{Pt}$ NPs decorated $\mathrm{SiO}_{2}$ spheres and other dielectric spheres. In addition, the dielectric spheres display a strong resonance cooperative effect with plasmonic $\mathrm{Au}$ and $\mathrm{Ag}$ NPs, ${ }^{\mathbf{2 1 , 2 3}}$ leading to their more efficient broadband light absorption than supported Pt NPs, especially in the visible-near infrared (vis-NIR) region (Fig. S8†). This confirms that the photoabsorption of both plasmonic and nonplasmonic metals can be tuned by interfacial photon management, which closely depends on the properties of the surrounding medium, such as the diameter of spherical supports, and the combination of the SPR effect with the nearfield scattering optical model gives rise to more efficient light harvesting capability of metal NPs. By jointly studying the absorption modes of $\mathrm{SiO}_{2}$ supported $\mathrm{Au}, \mathrm{Ag}$, and Pt NPs (Fig. S9†), the variation trends of the absorption maxima with increasing the diameter of $\mathrm{SiO}_{2}$ spheres are summarized in Fig. S9c. $\dagger$ As is clearly seen, in order to generate an efficient cooperative effect between near-field scattering and SPR absorption of $\mathrm{Au}$ NPs, the diameter of $\mathrm{SiO}_{2}$ spheres should be set at $\sim 300 \mathrm{~nm}$. With regard to producing distinct NIR light $(\lambda>$ $800 \mathrm{~nm}$ ) absorption peaks, the diameter of $\mathrm{SiO}_{2}$ spheres should be larger than $420 \mathrm{~nm}$.

\section{Broadband light driven catalysis}

To detect whether the broad-spectrum light absorption is able to promote solar-to-chemical energy conversion, the photocatalytic performances of the samples were examined under longer-wavelength vis-NIR light $(410 \mathrm{~nm}<\lambda<1100 \mathrm{~nm})$ irradiation. Fig. 3a shows the photoactivity of the bare $\mathrm{SiO}_{2}$, metal
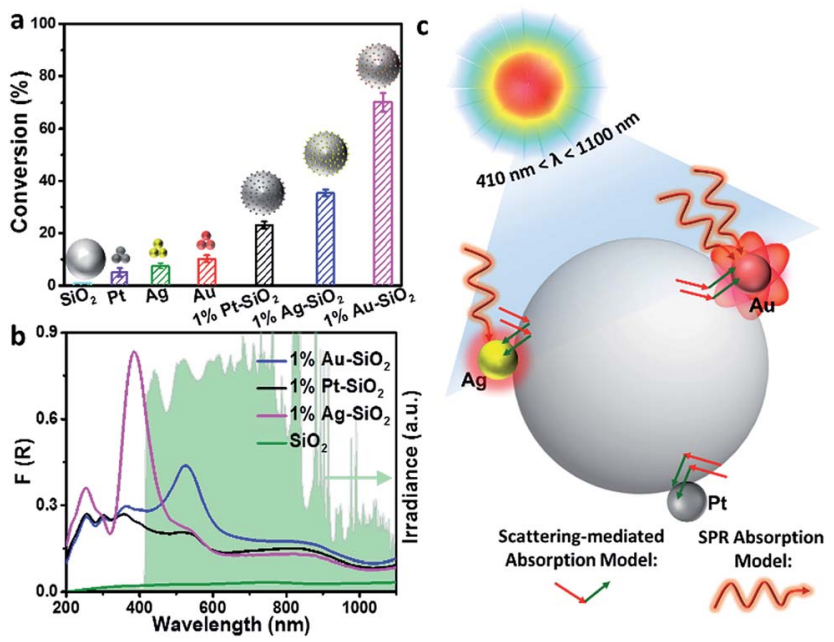

Fig. 3 (a) Photoreduction of 4-nitroaniline (4-NA) over bare $\mathrm{SiO}_{2}$, metal NPs, and $1 \% \mathrm{M}-\mathrm{SiO}_{2}(\mathrm{M}=\mathrm{Au}, \mathrm{Ag}, \mathrm{Pt})$ under visible-near infrared (vis-NIR) light (410 $\mathrm{nm}<\lambda<1100 \mathrm{~nm}$ ) irradiation for $5 \mathrm{~h}$. The insets of (a) show the model of the corresponding samples. Error bars represent the standard deviation calculated from triplicate experiments. (b) Ultraviolet-visible-near infrared (UV-vis-NIR) diffuse reflectance spectra (DRS) of $\mathrm{SiO}_{2}$ and $1 \% \mathrm{M}-\mathrm{SiO}_{2}$. The green area in (b) shows the spectrum of the irradiation source. (c) Schematic showing the mechanism of broadband optical absorption enhancement in $\mathrm{M}-\mathrm{SiO}_{2}$ composites. The diameter of $\mathrm{SiO}_{2}$ is $450 \mathrm{~nm}$.
NPs, and $\mathrm{SiO}_{2}$ supported metal NPs ( $\mathrm{M}-\mathrm{SiO}_{2}, \mathrm{M}=\mathrm{Au}, \mathrm{Ag}$ or Pt) composites with the same $\mathrm{SiO}_{2}$ diameter of $450 \mathrm{~nm}$ toward photoreduction of 4-nitroaniline (4-NA) at room temperature and under anaerobic conditions. It is seen that the bare $\mathrm{SiO}_{2}$ shows negligible photoactivity because it has no light harvesting capability in the vis-NIR region (Fig. 3b). By contrast, 1\% M$\mathrm{SiO}_{2}$ exhibits obvious activity under the same conditions, among which $1 \% \mathrm{Au}-\mathrm{SiO}_{2}$ and $1 \% \mathrm{Ag}-\mathrm{SiO}_{2}$ samples disclose enhanced photoactivity as compared to bare $\mathrm{Au}, \mathrm{Ag}, \mathrm{Pt}$ and even $1 \% \mathrm{Pt}-\mathrm{SiO}_{2}$, due to their largely enhanced broad-spectrum light absorption in the vis-NIR spectral range (Fig. 3b) resulting from the combination of the near-field scattering-mediated optical absorption model with the SPR model (Fig. 3c). The main SPR absorption peak of $1 \% \mathrm{Ag}-\mathrm{SiO}_{2}$ is located in the ultraviolet region, which accounts for its lower activity than $1 \% \mathrm{Au}-\mathrm{SiO}_{2}$ under vis-NIR light irradiation. These results indicate that the concurrent optical models are able to cooperatively contribute to the activity enhancement of the plasmonic $\mathrm{Au}-\mathrm{SiO}_{2}$ composite.

The influence of $\mathrm{SiO}_{2}$ size on the photoactivity was studied for $\mathrm{Au}-\mathrm{SiO}_{2}$ with four typical $\mathrm{SiO}_{2}$ diameters of 150, 300, 450 and $600 \mathrm{~nm}$. According to Fig. S9c, $\dagger \mathrm{Au}-\mathrm{SiO}_{2}$ with $\mathrm{a} \mathrm{SiO}_{2}$ diameter of $150 \mathrm{~nm}$ has a very weak interface-induced absorption enhancement in the vis-NIR region, whereas that with a $\mathrm{SiO}_{2}$ diameter of $300 \mathrm{~nm}$ possesses an efficient cooperative effect between near-field scattering and SPR absorption of Au NPs in the visible region. Further increasing the diameter of $\mathrm{SiO}_{2}$ to 450 or $600 \mathrm{~nm}$ leads to pronounced vis-NIR light absorption, but a weak cooperative effect. The above results can also be substantiated by the DRS spectra of the composites. As shown in Fig. 4a, the $\mathrm{Au}-\mathrm{SiO}_{2}$ composite with a core diameter of $300 \mathrm{~nm}$ exhibits the strongest SPR absorption intensity among all the samples, but weaker NIR light absorption than $\mathrm{Au}-\mathrm{SiO}_{2}$ with $\mathrm{SiO}_{2}$ diameters of 450 and $600 \mathrm{~nm}$. The photocatalytic activities of the samples, as disclosed in Fig. 4b, show that Au$\mathrm{SiO}_{2}$ with $\mathrm{a} \mathrm{SiO}_{2}$ diameter of $450 \mathrm{~nm}$ exhibits the highest activity. Considering that all the samples contain the same weight content of $\mathrm{Au}$ (i.e., 1\%), the highest photocatalytic activity of $\mathrm{Au}-\mathrm{SiO}_{2}$ with a $\mathrm{SiO}_{2}$ diameter of $450 \mathrm{~nm}$ can be attributed to the fact that this specific diameter of $\mathrm{SiO}_{2}$ enables the efficient photoabsorption of $\mathrm{Au}-\mathrm{SiO}_{2}$ both in the SPR model and near-field scattering-mediated absorption model. Unless specifically mentioned, the diameter of $\mathrm{SiO}_{2}$ is fixed at $450 \mathrm{~nm}$ in the subsequent experiments.

The photoactivity of $\mathrm{Au}-\mathrm{SiO}_{2}$ and $\mathrm{Au}-\mathrm{SiO}_{2} @ \mathrm{TiO}_{2}$ with different $\mathrm{Au}$ weight contents is shown in Fig. 4c. The conversion of 4-NA is gradually improved with increasing $\mathrm{Au}$ weight content. It is worth noting that due to the limitation of the electrostatic assembly method, the maximum load-bearing capacity of metal NPs is about 5\% Au weight content over the surface of $\mathrm{SiO}_{2}$. Au-SiO $\mathrm{STiO}_{2}$ exhibits higher activity than $\mathrm{Au}-$ $\mathrm{SiO}_{2}$ with the same amount of Au loading. For example, 92\% conversion of 4-NA is obtained over $5 \% \mathrm{Au}-\mathrm{SiO}_{2} @ \mathrm{TiO}_{2}$ with visNIR light irradiation for $2 \mathrm{~h}$, which is much higher than that of $5 \% \mathrm{Au}-\mathrm{SiO}_{2}$ (ca. 38\%).

Since the bare $\mathrm{SiO}_{2}$ and $\mathrm{SiO}_{2} @ \mathrm{TiO}_{2}$ core-shell composite show no photoactivity for the conversion of 4-NA (Fig. 4c), the 

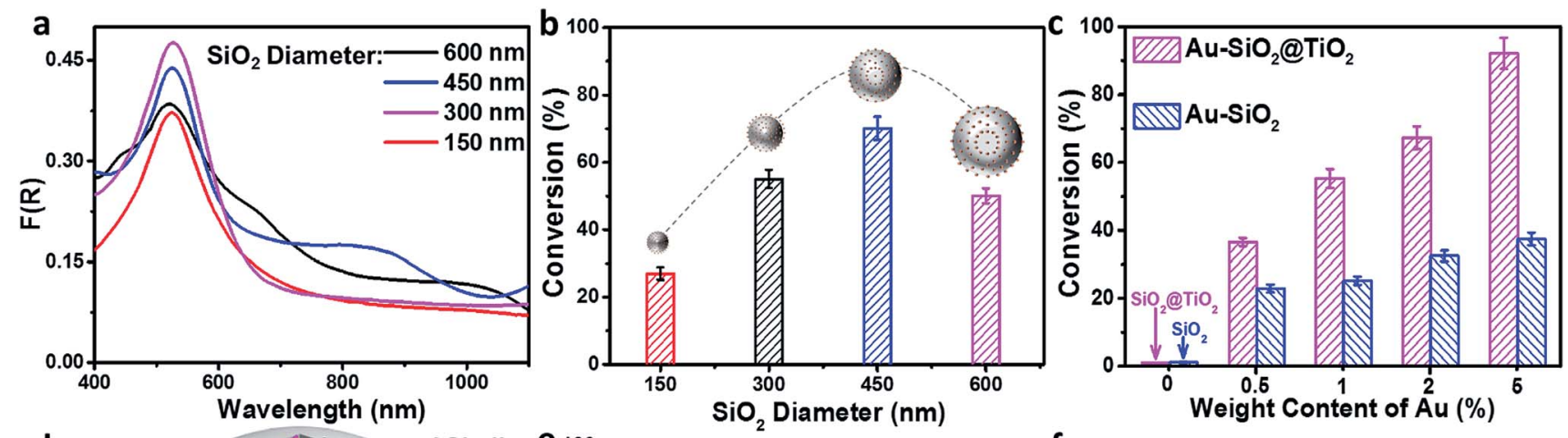

d
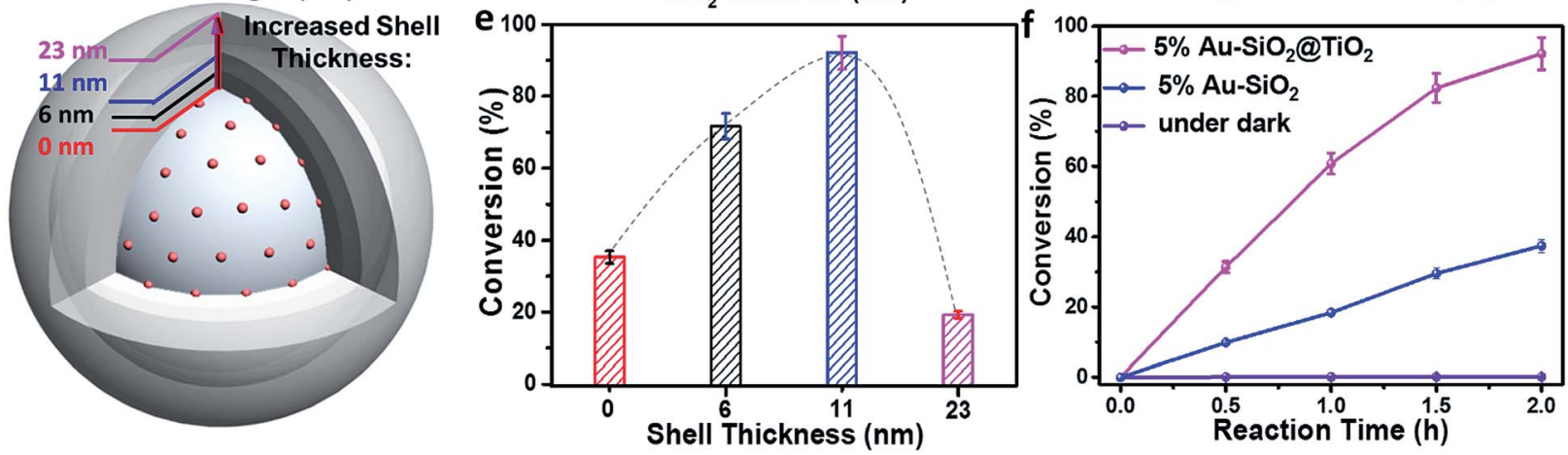

Fig. 4 (a) Ultraviolet-visible-near infrared (UV-vis-NIR) diffuse reflectance spectra (DRS) of $1 \% \mathrm{Au}-\mathrm{SiO}_{2}$ with different diameters of $\mathrm{SiO}{ }_{2}$ spheres. (b) Photoreduction of 4-nitroaniline (4-NA) over $1 \% \mathrm{Au}-\mathrm{SiO}_{2}$ with different diameters of $\mathrm{SiO}_{2}$ spheres under visible-near infrared (vis-NIR) light $(410 \mathrm{~nm}<\lambda<1100 \mathrm{~nm}$ ) irradiation for $5 \mathrm{~h}$. The insets of (b) show the model of the corresponding samples. (c) Photoreduction of 4-NA over Au$\mathrm{SiO}_{2}$ and $\mathrm{Au}-\mathrm{SiO}_{2} \mathrm{aTiO}_{2}$ with different weight contents of Au under vis-NIR light irradiation for $2 \mathrm{~h}$. (d) $\mathrm{Schematic}$ model of $5 \% \mathrm{Au}-\mathrm{SiO} \mathrm{OTiO}_{2}$ with different shell thicknesses. (e) Photoreduction of 4-NA over $5 \% \mathrm{Au}-\mathrm{SiO}_{2} \mathrm{QTiO}_{2}$ with different shell thicknesses under vis-NIR light irradiation for $2 \mathrm{~h}$. (f) Time-online profiles of photoreduction of 4-NA over optimal $5 \% \mathrm{Au}-\mathrm{SiO}_{2}$ and $5 \% \mathrm{Au}-\mathrm{SiO}_{2} \mathrm{aTiO}_{2}$ under vis-NIR light irradiation or over $5 \% \mathrm{Au}-\mathrm{SiO}_{2} \mathrm{CTiO}_{2}$ under dark conditions. Error bars represent the standard deviation calculated from triplicate experiments. The TiO $\mathrm{T}_{2}$ shell thickness of $5 \% \mathrm{Au}-\mathrm{SiO}_{2} \mathrm{QTiO}_{2}$ is $11 \mathrm{~nm}$.

higher photoactivity of $\mathrm{Au}-\mathrm{SiO}_{2} @ \mathrm{TiO}_{2}$ than $\mathrm{Au}-\mathrm{SiO}_{2}$ should be closely linked with the interfacial interaction between the $\mathrm{TiO}_{2}$ shell and Au NPs layer. On the basis of such consideration, we examined the photoactivity of $5 \% \mathrm{Au}-\mathrm{SiO}_{2} @ \mathrm{TiO}_{2}$ with different thicknesses of the $\mathrm{TiO}_{2}$ shell (e.g., 6, 11 and $23 \mathrm{~nm}$, Fig. 4d). The results (Fig. 4e) reveal that $5 \% \mathrm{Au}-\mathrm{SiO}_{2} @ \mathrm{TiO}_{2}$ with a shell thickness of $11 \mathrm{~nm}$ exhibits the highest photoactivity among these samples. An excess amount of $\mathrm{TiO}_{2}$ coating in $5 \% \mathrm{Au}-$ $\mathrm{SiO}_{2} @ \mathrm{TiO}_{2}$ could lead to the hot charge carriers generated at the vicinity of Au NPs hardly reaching the $\mathrm{TiO}_{2}$ shell surface, where the redox catalysis reaction takes place, ${ }^{21}$ thus suppressing the photoactivity. Fig. 4f shows the time-online profiles of photoreduction of 4-NA over the optimal $5 \% \mathrm{Au}-$ $\mathrm{SiO}_{2}$ and $5 \% \mathrm{Au}-\mathrm{SiO}_{2} @ \mathrm{TiO}_{2}$. With extending the irradiation time, the conversion of 4-NA increases correspondingly. A control experiment for testing the activity of the $5 \% \mathrm{Au}-$ $\mathrm{SiO}_{2} @ \mathrm{TiO}_{2}$ sample in the dark shows no conversion of 4-NA. These results indicate that the reduction of 4-NA can be attributed to a characteristic photocatalytic process. ${ }^{45-47}$ The photoactivity enhancement of $5 \% \mathrm{Au}-\mathrm{SiO}_{2} @ \mathrm{TiO}_{2}$ was also confirmed by the conversion of other aromatic nitro compounds (Table S1 $\dagger$ ) and benzylic alcohols (Table S2 $\dagger$ ) and photocatalytic $\mathrm{CO}_{2}$ reduction (Fig. S10a ††) and water splitting (Fig. S10b†) under vis-NIR light irradiation, suggesting promising scope to adopt this core-shell ensemble for realizing broad-spectrum light driven artificial photosynthesis. In addition, the recycling photoactivity test indicates that the presence of the $\mathrm{TiO}_{2}$ shell can distinctly enhance the reusability and stability of the $\mathrm{Au}-\mathrm{SiO}_{2} @ \mathrm{TiO}_{2}$ photocatalyst during the reaction process (Fig. S11†).

\section{Mechanism of the photoactivity enhancement}

Wavelength-dependent action spectrum analysis was performed to further verify the contribution of Au NPs to the photoactivity of $\mathrm{Au}-\mathrm{SiO}_{2} @ \mathrm{TiO}_{2}$. As shown in Fig. 5a, the action spectrum of the optimal 5\% $\mathrm{Au}-\mathrm{SiO}_{2} @ \mathrm{TiO}_{2}$ sample correlates well with its broadband light absorption. The conversion of 4NA reaches its maximum value with the irradiation of monochromatic light centered at $540 \mathrm{~nm}$. When the light source is switched to $905 \mathrm{~nm}$ NIR light, the $5 \% \mathrm{Au}-\mathrm{SiO}_{2} @ \mathrm{TiO}_{2}$ hybrid also exhibits considerable photoactivity $(12 \%$ conversion of 4-NA). These results suggest that the observed activity of $\mathrm{Au}-$ $\mathrm{SiO}_{2} @ \mathrm{TiO}_{2}$, even under NIR irradiation, is initiated by the specific optical absorption of $\mathrm{Au}$ NPs in the $\mathrm{Au}-\mathrm{SiO}_{2} @ \mathrm{TiO}_{2}$ composite. ${ }^{14,18,46,48}$ To identify the contribution of the interfacial photon scattering from the internal $\mathrm{SiO}_{2}$ to the promoted solar-to-chemical energy conversion over $\mathrm{Au}-\mathrm{SiO}_{2} @ \mathrm{TiO}_{2}$, we prepared an $\mathrm{Au} @ \mathrm{TiO}_{2}$ yolk-shell structure by removing the $\mathrm{SiO}_{2}$ core from $\mathrm{Au}-\mathrm{SiO}_{2} @ \mathrm{TiO}_{2}$ (Fig. S12†). The comparisons between 

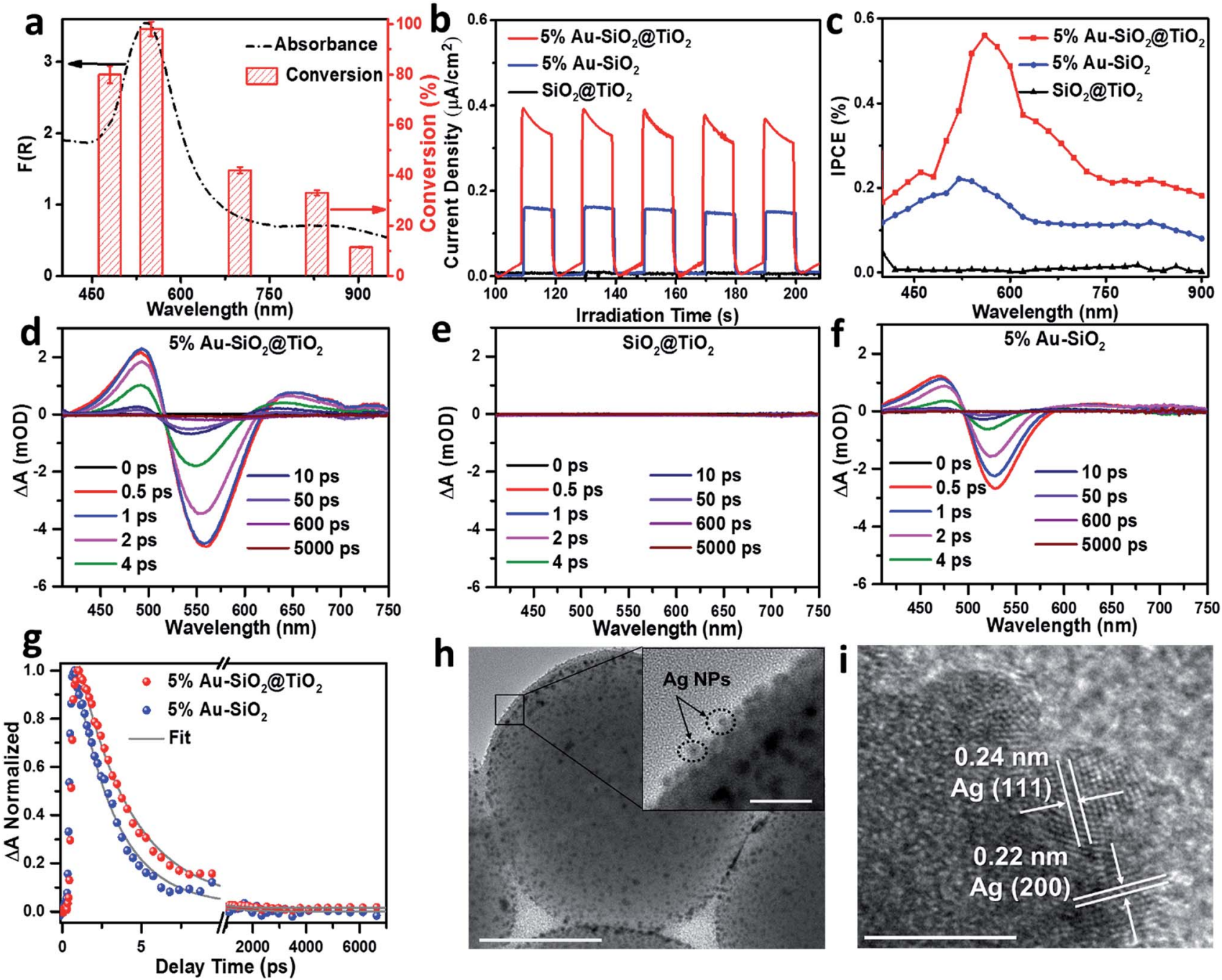

h
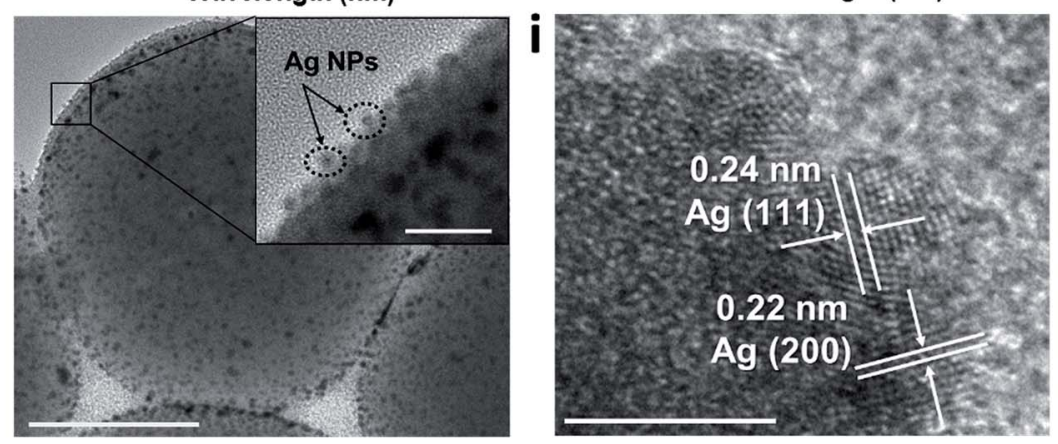

Fig. 5 (a) Absorption spectrum (left axis) and action spectrum (right axis) of $5 \% \mathrm{Au}-\mathrm{SiO}_{2} \mathrm{QTiO}$ for the reduction of 4-nitroaniline (4-NA). The irradiation time with different monochromatic light is $10 \mathrm{~h}$. The power density of different monochromatic light is $30.0 \mathrm{~mW} \mathrm{~cm}^{-2}$. Error bars represent the standard deviation calculated from triplicate experiments. (b) Transient photocurrent-time $(I-t)$ curves under visible-near infrared

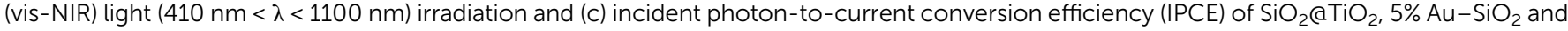
$5 \% \mathrm{Au}-\mathrm{SiO}_{2} \mathrm{aTiO}_{2}$ electrodes. Transient absorption (TA) spectra of (d) $5 \% \mathrm{Au}-\mathrm{SiO}_{2} \mathrm{aTiO}_{2}$, (e) $\mathrm{SiO}_{2} \mathrm{aTiO}_{2}$ and (f) $5 \% \mathrm{Au}-\mathrm{SiO} 2$ at indicated delay time windows after $400 \mathrm{~nm}$ excitation. (g) TA kinetics for $5 \% \mathrm{Au}-\mathrm{SiO}_{2} \mathrm{CTiO}$ and $5 \% \mathrm{Au}-\mathrm{SiO}_{2}$ after $400 \mathrm{~nm}$ excitation and detection at $524 \mathrm{~nm}$. (h) Transmission electron microscopy (TEM) image of 5\% Au- $\mathrm{SiO}_{2} \mathrm{OTiO}_{2}$ after photodeposition of Ag NPs. Scale bar, $200 \mathrm{~nm}$. The boxed area in the inset of (h) indicates the presence of Ag NPs. Scale bar, $20 \mathrm{~nm}$. (i) High-resolution TEM (HRTEM) image of $5 \% \mathrm{Au}^{-\mathrm{SiO}} \mathrm{O}_{2} \mathrm{aTiO} \mathrm{O}_{2}$ after photodeposition of Ag NPs. Scale bar, $5 \mathrm{~nm}$. The $\mathrm{TiO}_{2}$ shell thickness of $5 \% \mathrm{Au}-\mathrm{SiO}_{2} \mathrm{QTiO}_{2}$ is $11 \mathrm{~nm}$.

their light absorption and photoactivity indicate that both the optical absorption and photoactivity of $\mathrm{Au}-\mathrm{SiO}_{2} @ \mathrm{TiO}_{2}$ are higher than those of $\mathrm{Au} @ \mathrm{TiO}_{2}$, which demonstrates that the interfacial photon scattering from the $\mathrm{SiO}_{2}$ core can intensify the light absorption of Au NPs to improve the efficiency of generation and separation of hot charge carriers to drive the photocatalytic reactions.

The photoelectrochemical (PEC) measurements under visNIR light $(410 \mathrm{~nm}<\lambda<1100 \mathrm{~nm})$ irradiation also confirmed the enhanced solar energy conversion efficiency of $\mathrm{Au}-\mathrm{SiO}_{2} @ \mathrm{TiO}_{2}$. The photocurrent generated by optimal 5\% Au- $\mathrm{SiO}_{2} @ \mathrm{TiO}_{2}$ under vis-NIR light irradiation is almost 2 times as high as that

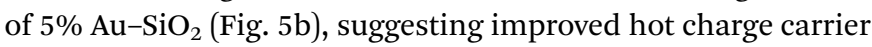

generation and separation induced by the coated $\mathrm{TiO}_{2}$ shell. ${ }^{37}$ The $\mathrm{SiO}_{2} @ \mathrm{TiO}_{2}$ electrode generates negligible photocurrent under identical conditions, since it cannot absorb vis-NIR light, which is in line with the photoactivity measurements (Fig. 4c). The incident photon-to-current efficiency (IPCE) value of 5\% $\mathrm{Au}-\mathrm{SiO}_{2} @ \mathrm{TiO}_{2}$ is higher than that of $5 \% \mathrm{Au}-\mathrm{SiO}_{2}$ and $\mathrm{SiO}_{2}$ @$\mathrm{TiO}_{2}$ in the entire vis-NIR range (Fig. 5c). The surface area and adsorption experimental analysis (Fig. S13 and Table S3†) suggest that the coating of the $\mathrm{TiO}_{2}$ shell has no significant effect on the adsorption capacity of $\mathrm{Au}-\mathrm{SiO}_{2} @ \mathrm{TiO}_{2}$ as compared to $\mathrm{Au}-\mathrm{SiO}_{2}$. The above results, together with the optical properties of the samples, illustrate that the primary role of the $\mathrm{TiO}_{2}$ shell with an appropriate thickness is to further enhance the 
light harvesting capability of $\mathrm{Au}-\mathrm{SiO}_{2}$ and it contributes to extracting hot electrons from photoexcited Au NPs, thereby leading to enhanced photoactivity.

Transient absorption (TA) spectroscopy was employed to measure the lifetime of the hot electrons, which in turn provides direct evidence for the electron transfer direction. ${ }^{15,49-51}$ Fig. 5d shows the absorption spectroscopy of optimal $5 \% \mathrm{Au}-\mathrm{SiO}_{2} @ \mathrm{TiO}_{2}$ after $400 \mathrm{~nm}$ excitation, where a long-lived exciton state can be clearly observed at wavelengths between 410 and $520 \mathrm{~nm}$ and a bleach signal located at $\sim 560 \mathrm{~nm}$ also appears. Since no signal is observed for $\mathrm{SiO}_{2} @ \mathrm{TiO}_{2}$ due to the wide bandgap of $\mathrm{TiO}_{2}$ and $\mathrm{SiO}_{2}$ (Fig. 5e), the observed transient absorption for $5 \% \mathrm{Au}-\mathrm{SiO}_{2} @ \mathrm{TiO}_{2}$ can be assigned to the excited Au NPs. ${ }^{49}$ In comparison with $5 \% \mathrm{Au}-\mathrm{SiO}_{2}$ (Fig. 5f), the intensity of the absorption signal of $5 \% \mathrm{Au}-\mathrm{SiO}_{2} @ \mathrm{TiO}_{2}$ is increased, indicating the enhanced optical absorption and generation efficiency of hot electrons, which can be assigned to the contribution from near-field interfacial photon scattering collaboratively tuned by the $\mathrm{SiO}_{2}$ core and $\mathrm{TiO}_{2}$ shell. ${ }^{15}$ To evaluate the decay kinetics of photogenerated electron-hole pairs in the Au NPs component, the TA traces were fitted using a biexponential function as displayed in Fig. $5 \mathrm{~g}$, and their lifetimes $\left(\tau_{\mathrm{i}}\right)$ and amplitudes $\left(A_{\mathrm{i}}\right)$ are summarized in Table S4. $\dagger$ The TA signal relaxation is dominated by a fast decay due to the hot electron relaxations via electron-electron and electron-phonon scatterings, followed by a slower decay arising from the phonon-phonon and phonon-solvent interactions. ${ }^{50}$ The $5 \%$ $\mathrm{Au}-\mathrm{SiO}_{2}$ sample exhibits fast decay with a time scale of 2.5 ps (94\%), which is consistent with previous reports on colloidal $\mathrm{Au}{ }^{49,50}$ The electrons transferring from the excited $\mathrm{Au}$ to $\mathrm{TiO}_{2}$ delay the exciton recombination process in Au NPs, giving rise to a prolonged lifetime of hot electrons within $5 \% \mathrm{Au}-$ $\mathrm{SiO}_{2} @ \mathrm{TiO}_{2} \cdot{ }^{\mathbf{4 9 , 5 1}}$

Thus far, a mechanism for interfacial hot charge carrier generation and transfer involved in photocatalytic redox reactions has been proposed, as illustrated in Fig. S14. $\dagger$ When Au$\mathrm{SiO}_{2} @ \mathrm{TiO}_{2}$ with a core-shell structure is irradiated with vis-NIR light, the Au NPs can simultaneously absorb the incident light and the scattered light at the near-field of the $\mathrm{SiO}_{2}$ dielectric surface to generate charge carriers. The energetic hot electrons are transferred to the conduction band $\left(E_{\mathrm{CB}}\right)$ of the $\mathrm{TiO}_{2}$ shell for driving the surface reduction reactions (e.g., reduction of aromatic nitro compounds, $\mathrm{H}_{2}$ evolution from water splitting and reduction of $\mathrm{CO}_{2}$ ), while the holes located below the Fermi level $\left(E_{\mathrm{f}}\right)$ of $\mathrm{Au}$ NPs are tunneled to the surface of $\mathrm{TiO}_{2}$ to react with the electron donors (e.g., benzylic alcohols and hole scavengers). ${ }^{6,18,52,53}$ We also performed a probe experiment of adding silver nitrate into the aqueous $\mathrm{Au}-\mathrm{SiO}_{2} @ \mathrm{TiO}_{2}$ suspension to further verify the transfer of electrons from Au NPs to the $\mathrm{TiO}_{2}$ shell under vis-NIR light irradiation..$^{52,53}$ We can clearly observe the $\mathrm{Ag}$ particles photodeposited at the external surface of the $\mathrm{TiO}_{2}$ shell from the TEM images (Fig. $5 \mathrm{~h}$ and i). The lattice fringes with 0.22 and $0.24 \mathrm{~nm}$ spacing are indexed to the (200) and (111) crystal planes of $\mathrm{Ag}$, respectively (Fig. 5i). In addition, the DRS spectrum of 5\% $\mathrm{Au}-\mathrm{SiO}_{2} @ \mathrm{TiO}_{2}$ after photodeposition of $\mathrm{Ag}$ (Fig. S15†) shows a clear absorption increase in the range of 300 to $500 \mathrm{~nm}$, which is due to the reduction of silver ions to metallic Ag on the surface of the $\mathrm{TiO}_{2}$ shell. ${ }^{53}$ This suggests that the hot electrons photoexcited from Au NPs are able to transfer to the $\mathrm{TiO}_{2}$ shell, thereby reducing silver nitrate to metallic Ag particles.

\section{Conclusions}

In conclusion, we have demonstrated that the optical absorption and hot charge carrier transport of plasmonic metal NPs can be delicately engineered by constructing a 3D core-shell composite. The combination of a near-field scattering promoted optical absorption model with the SPR model allows tuning of the optical absorption of plasmonic metal NPs across the UV-vis-NIR region, and results in enhanced interfacial hot charge carrier generation and transfer from metal NPs. The dielectric environment significantly affects the light absorption, hot charge carrier injection and photoactivity of metal NPs. Considering the generality that optical properties can be tuned in a broad-spectral range in such a core-shell structure by varying both the support and metal NPs, this strategy by managing the interfacial photons offers a controllable and flexible platform to modulate the optoelectronic properties of materials for promising solar energy conversion.

\section{Conflicts of interest}

There are no conflicts to declare.

\section{Acknowledgements}

The support from the National Natural Science Foundation of China (NSFC) (21872029, U1463204, and 21173045), the Award Program for Minjiang Scholar Professorship, the Natural Science Foundation (NSF) of Fujian Province for Distinguished Young Investigator Rolling Grant (2017J07002), the Independent Research Project of State Key Laboratory of Photocatalysis on Energy and Environment (No. 2014A05), and the 1st Program of Fujian Province for Top Creative Young Talents is gratefully acknowledged.

\section{Notes and references}

1 S. Linic, U. Aslam, C. Boerigter and M. Morabito, Nat. Mater., 2015, 14, 567-576.

2 G. Baffou and R. Quidant, Chem. Soc. Rev., 2014, 43, 38983907.

3 X. Liu, J. Iocozzia, Y. Wang, X. Cui, Y. Chen, S. Zhao, Z. Li and Z. Lin, Energy Environ. Sci., 2017, 10, 402-434.

4 N. Zhang, C. Han, X. Fu and Y.-J. Xu, Chem, 2018, 4, 18321861.

5 P. Zhang, T. Wang and J. Gong, Adv. Mater., 2015, 27, 53285342.

6 J. Zhang, X. Jin, P. I. Morales-Guzman, X. Yu, H. Liu, H. Zhang, L. Razzari and J. P. Claverie, ACS Nano, 2016, 10, 4496-4503.

7 M. Lee, J. U. Kim, K. J. Lee, S. Ahn, Y.-B. Shin, J. Shin and C. B. Park, ACS Nano, 2015, 9, 6206-6213. 
8 A.-K. U. Michel, D. N. Chigrin, T. W. W. Maß, K. Schönauer, M. Salinga, M. Wuttig and T. Taubner, Nano Lett., 2013, 13, 3470-3475.

9 G. V. Naik, V. M. Shalaev and A. Boltasseva, Adv. Mater., 2013, 25, 3264-3294.

10 M. Wang, M. Ye, J. Iocozzia, C. Lin and Z. Lin, Adv. Sci., 2016, 3, 1600024.

11 Y.-C. Pu, G. Wang, K.-D. Chang, Y. Ling, Y.-K. Lin, B. C. Fitzmorris, C.-M. Liu, X. Lu, Y. Tong and J. Z. Zhang, Nano Lett., 2013, 13, 3817-3823.

12 M. B. Cortie and A. M. McDonagh, Chem. Rev., 2011, 111, 3713-3735.

13 H. Huang, L. Zhang, Z. Lv, R. Long, C. Zhang, Y. Lin, K. Wei, C. Wang, L. Chen, Z.-Y. Li, Q. Zhang, Y. Luo and Y. Xiong, J. Am. Chem. Soc., 2016, 138, 6822-6828.

14 T. Majima, J. Am. Chem. Soc., 2014, 137, 948-957.

15 J. Guo, Y. Zhang, L. Shi, Y. Zhu, M. F. Mideksa, K. Hou, W. Zhao, D. Wang, M. Zhao, X. Zhang, J. Lv, J. Zhang, X. Wang and Z. Tang, J. Am. Chem. Soc., 2017, 139, 1796417972.

16 D. F. Swearer, H. Zhao, L. Zhou, C. Zhang, H. Robatjazi, J. M. P. Martirez, C. M. Krauter, S. Yazdi, M. J. McClain and E. Ringe, Proc. Natl. Acad. Sci. U. S. A., 2016, 113, 8916-8920.

17 X. Li, J. Iocozzia, Y. Chen, S. Zhao, X. Cui, W. Wang, H. Yu, S. Lin and Z. Lin, Angew. Chem., Int. Ed., 2018, 57, 2046-2070.

18 N. Zhang, C. Han, Y.-J. Xu, J. J. Foley IV, D. Zhang, J. Codrington, S. K. Gray and Y. Sun, Nat. Photonics, 2016, 10, 473-482.

19 I. Alessandri, J. Am. Chem. Soc., 2013, 135, 5541-5544.

20 S. Son, S. H. Hwang, C. Kim, J. Y. Yun and J. Jang, ACS Appl. Mater. Interfaces, 2013, 5, 4815-4820.

21 S. Sun, H. Liu, L. Wu, C. E. Png and P. Bai, ACS Catal., 2014, 4, 4269-4276.

22 N. Eldabagh, M. Micek, A. E. DePrince and J. J. Foley, J. Phys. Chem. C, 2018, 122, 18256-18265.

23 J. Codrington, N. Eldabagh, K. Fernando and J. J. Foley IV, ACS Photonics, 2017, 4, 552-559.

24 Q. Zhang, D. Q. Lima, I. Lee, F. Zaera, M. Chi and Y. Yin, Angew. Chem., Int. Ed., 2011, 50, 7226-7230.

25 B. Y. Guan, L. Yu, J. Li and X. W. Lou, Sci. Adv., 2016, 2, e1501554.

26 M. W. Knight, S. Heidar, N. Peter and N. J. Halas, Science, 2011, 332, 702-704.

27 K.-H. Chen, Y.-C. Pu, K.-D. Chang, Y.-F. Liang, C.-M. Liu, J.-W. Yeh, H.-C. Shih and Y.-J. Hsu, J. Phys. Chem. C, 2012, 116, 19039-19045.

28 P. K. Jain and M. A. El-Sayed, Nano Lett., 2008, 8, 4347-4352.

29 J. Yang, Y. Li, L. Zu, L. Tong, G. Liu, Y. Qin and D. Shi, ACS Appl. Mater. Interfaces, 2015, 7, 8200-8208.
30 T. J. Norman, C. D. Grant, D. Magana, J. Z. Zhang, J. Liu, D. Cao, F. Bridges and A. Van Buuren, J. Phys. Chem. B, 2002, 106, 7005-7012.

31 H. Jung, H. Cha, D. Lee and S. Yoon, ACS Nano, 2015, 9, 12292-12300.

32 R. W. Taylor, T.-C. Lee, O. A. Scherman, R. Esteban, J. Aizpurua, F. M. Huang, J. J. Baumberg and S. Mahajan, ACS Nano, 2011, 5, 3878-3887.

33 X. Shi, Z. Lou, P. Zhang, M. Fujitsuka and T. Majima, ACS Appl. Mater. Interfaces, 2016, 8, 31738-31745.

34 Y. Lu, H. Yu, S. Chen, X. Quan and H. Zhao, Environ. Sci. Technol., 2012, 46, 1724-1730.

35 Z. Zhang, L. Zhang, M. N. Hedhili, H. Zhang and P. Wang, Nano Lett., 2012, 13, 14-20.

36 Y. H. Jang, Y. J. Jang, S. T. Kochuveedu, M. Byun, Z. Lin and D. H. Kim, Nanoscale, 2014, 6, 1823-1832.

37 M. Ye, H. Zhou, T. Zhang, Y. Zhang and Y. Shao, Chem. Eng. J., 2013, 226, 209-216.

38 L. Kong, G. Duan, G. Zuo, W. Cai and Z. Cheng, Mater. Chem. Phys., 2010, 123, 421-426.

39 X. Ma, K. Zhao, H. Tang, Y. Chen, C. Lu, W. Liu, Y. Gao, H. Zhao and Z. Tang, Small, 2014, 10, 4664-4670.

40 M. Wang, X. Pang, D. Zheng, Y. He, L. Sun, C. Lin and Z. Lin, J. Mater. Chem. A, 2016, 4, 7190-7199.

41 K. Li, N. J. Hogan, M. J. Kale, N. J. Halas, P. Nordlander and P. Christopher, Nano Lett., 2017, 17, 3710-3717.

42 L. Zhang, H. Jing, G. Boisvert, J. Z. He and H. Wang, ACS Nano, 2012, 6, 3514-3527.

43 X. Cheng, R. Sun, L. Yin, Z. Chai, H. Shi and M. Gao, Adv. Mater., 2017, 29, 1604894.

44 P. K. Jain, K. S. Lee, I. H. El-Sayed and M. A. El-Sayed, J. Phys. Chem. B, 2006, 110, 7238-7248.

45 Z. Yin, J. Guo, S. Lin, Y. Zhu, H. Ke, Y. Zheng and Z. Tang, Sci. Adv., 2017, 3, e1701162.

46 C. Han, Q. Quan, H. M. Chen, Y. Sun and Y.-J. Xu, Small, 2017, 13, 1602947.

47 X. Xie, N. Zhang, Z.-R. Tang and Y.-J. Xu, Chem. Sci., 2018, DOI: 10.1039/c8sc03679a.

48 S. Mubeen, J. Lee, N. Singh, S. Krämer, G. D. Stucky and M. Moskovits, Nat. Nanotechnol., 2013, 8, 247-251.

49 Y. Si, S. Cao, Z. Wu, Y. Ji, Y. Mi, X. Wu, X. Liu and L. Piao, Nano Energy, 2017, 41, 488-493.

50 Y. Kobayashi, Y. Nonoguchi, L. Wang, T. Kawai and N. Tamai, J. Phys. Chem. Lett., 2012, 3, 1111-1116.

51 X. Cai, L. Mao, S. Yang, K. Han and J. Zhang, ACS Energy Lett., 2018, 3, 932-939.

52 A. Li, P. Zhang, X. Chang, W. Cai, T. Wang and J. Gong, Small, 2015, 11, 1892-1899.

53 N. Zhou, L. Polavarapu, N. Gao, Y. Pan, P. Yuan, Q. Wang and Q.-H. Xu, Nanoscale, 2013, 5, 4236-4241. 